$\xi=-$ 娄

\title{
Framework for Patient Service Queue System for Decision Support System on Smart Health Care
}

\author{
Akim Manaor Hara Pardede ${ }^{1 *}$, Herman Mawengkang1, Muhammad Zarlis ${ }^{1}$, \\ T Tulus', Yani Maulita ${ }^{2}$, Achmad Fauzi ${ }^{2}$, N Novriyenni ${ }^{2}$ \\ ${ }^{1}$ Universitas Sumatera Utara, Medan, Indonesia \\ ${ }^{2}$ Sekolah Tinggi Manajemen Informatika dan Komputer Kaputama, Binjai, Indonesia \\ *Corresponding author E-mail: akimmhp@live.com
}

\begin{abstract}
Improving the service of patient care in hospitals is important for all, prioritizing patient safety in the event of a sudden or catastrophic attack, in which case the priority is to provide services to the patient. In such situations a decision system is needed, in order for the system to be right and not wrong to do a decision because the handling of this issue is closely related to the patient's life. The patient handling technology supports highly smart healthcare technology, which of course is part of the Smart city. The purpose of this research is to get Smart Health Care model with Decision Support System model approach in public health service, where Decision Support System model for Smart Health Care can solve health service problem in order to make maximum service for patient
\end{abstract}

Keywords: Decision Support System, Smart Health Care, Queue

\section{Introduction}

Smart Health Care is a smart hospital service system. Smart Health Care enables hospitals to give better service to patients. The Smart HealthCare system handles many of the hospital's existing systems, such as patient medical records, staff scheduling, availability of in-patient rooms, doctor's schedules, and much more data that the Smart HealthCare system can hand.

Improving the flow of patients during service or speeding up service to the patients is a way to improve health services. An efficient stream of patient care can improve service quality and improve resource utilization. A smart environment can facilitate individual experience in physical resources, such as hospitals. Meanwhile, a smart health environment can improve the flow of patient care through efficient scheduling policies and utilization of health resources through an optimal capacity plan. Xiao Chen et.al., discusses dynamic scheduling policies to improve patient flow, and efficient capacity schemes based on different patient streams. Decision support systems on such scheduling and capacity schemes can be built in smart hospital environments through wireless sensor networks and smart health care systems [1].

Aims to optimize the clinical workflow by personalizing case suitability (new patients) with appropriate diagnostic skills whether Clinical Decision Support Systems (CDSS), domain experts specializing in similar types of cases, or institutions other. In current clinical practice, patients are referred to an expert and ad-hoc manner based on one or more of the following factors: signs and symptoms of patient preference, patient or primary care physician, insurance plan, and physician availability. Their research developed a framework and related methods and algorithms that use semantic knowledge about patients to assess and recommend expertise with the goal of optimizing the process for diagnosing patients [2].
Modeling and simulation is an important tool in resolving epidemics (epidemic or outbreaks of disease in certain communities / regions in a number that exceeds normal or usual limits) to understand the spread of epidemics in connected tissues, some models are proposed and studied. Younsi did research in this regard by addressing the problem of epidemic dissemination in social networks by building and analyzing the nature of small world net [3].

Smarter health begins with better connections, better data, and faster and more detailed analysis. This means giving individuals an opportunity to have greater ownership of the patient, so that every professional has access to all relevant information and can make the right diagnosis and treatment decision as soon as possible. It also means switching from notes on paper, reducing medical errors and improving efficiency. And that means applying further analysis to a large amount of health data, to support improved public health outcomes.

\section{State of the Art}

Due to the rapid population growth, traditional health care is overwhelmed. There are not enough medical practitioners to meet the needs of the citizens. Many times hospitals make mistakes in dealing with infectious diseases. On many occasions patients receive the wrong medication. In many remote places on the planet that receive dequate health care is still a distant dream. Thus, with limited resources and increasing demand, traditional health needs must be smart, efficient and sustainable; That's where smart health comes in. Smart health care can be conceptualized as a combination of entities including traditional health care, intelligent biosensors, usable devices, information and communication technology (ICT), and intelligent ambulance systems. The idea of smart health care is presented in Figure 1. The idea of smart health care, described various components of smart health care include exist- 
ing body sensors, smart hospitals, and intelligent emergency responses. In smart hospitals, various mechanisms including ICT, cloud computing, smart phone applications, and advanced data analysis techniques, are used for their operations. Patient data can be performed in real-time at various offices in a smart hospital or even smart hospitals in different cities or cities. Medical technicians, nurses, and doctors can have access to test data without losing time in physically transferring the same information from one office to another. Similarly, different doctors can view information to make an assessment of the patient's condition. So a realtime decision about the patient's health condition and appropriate treatment can be done [4].

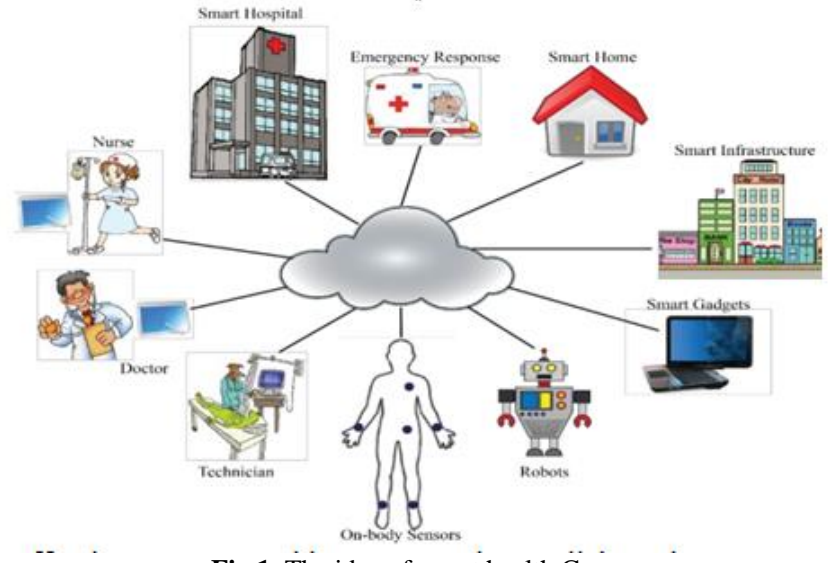

Fig 1. The idea of smart health Care

Effective Smart Health Care requires collaboration among many people and resources, including patients, doctors, and healthcare professionals, as well as management of hospital facilities [5] This collaboration is crucial for home health care arrangements, where patient family members may also be involved in the event that the patient can no longer act. The effectiveness of the collaboration, in turn, depends on communication and information among different people in this setting [6]. Poor efficiency in doctors and nurses' communication to patients and the inability to monitor the health of patients at home is a major contributing factor.

The Smart Heath system can facilitate community health management. Policies and decisions can be personalized (as needed) for every city and even district, based on data derived from the population, health, environmental, climate, available facilities, and existing infrastructure. Opportunities arising from extracting such data can optimize unlimited public health decision making [7]

This queue can occur due to arrival which is increasingly enlarged at times and can not be matched by service which exists. The long queue will be making people wait until finally got bored to even go. Influential factors against the queue and lineup his services are as follows [8] [9][10]:

1) Arrival Distribution, on the queue system, distribution arrival is factor important that have a big effect to smooth service. The distribution of arrivals is divided into two, that is :

a. Arrival on individual/single arrivals

b. Arrival in groups / bulk arrivals

Both components this should be get that attention adequate at the time of designing service system.

2) Time Service Distribution, distribution of service time related to how much service facilities that can provided. Time distribution service is divided into two important components, namely:

a. Individualized service / single Service

b. Group service / bulk service

3) Service facilities, service facilities are closely related with the queue line going formed. The design of this service facility can be divided into three forms, namely:

a. Shape series, in one line straight or circular lines.

b. Parallel form, in some cases a straight line between one with another parallel. c. Form a network station, which can designed in series with more than one service on every station. This form can be also done in parallel with different stations. With so form facilities service this also must calculated in the system queue.

4) Service discipline, service discipline is closely related with the order of service for customers entering the facility service.

5) Size in queue, the size of the customer queue will enter the service facility also need to be considered. There are two designs to choose from determine the size of the queue, namely :

a. The arrival size is not limited / infinite queue

b. The size of arrivals by limited / finite queue

6) Sources of callings, in the service facility, which is play a role as source the call can be a machine and humans. If there are any number the damaged machine then the source the call will be reduced and can not serve customers. So the problem is whether :

a. The call source is limited / finite calling source

b. Unlimited call source / infinite calling source

Decision Support System (DSS) represents the concept of the role of computers in the decision-making process. This term has become a call for researchers, practitioners and managers to argue that the field of Management Science and Management of Information Systems becomes a focus that need not be narrowed down. Like many shouts, the term is not well defined. For some authors, DSS implies an interactive system for use by managers. For others, the main issue is support, not systems [11], in which it can be concluded that decision support systems (DSS) are extracting raw data into information that supports decision-making in a business or organization.

By analyzing what researchers and developers have done, all the main purpose is how to get information about the health conditions of users of the device, in this case it should consider how the service users of the device if experiencing health problems, and what actions a smart device should be performed or a physician's action as a management decision-maker. The intelligent or smart device actions employed require a decisionsupport system model for smart health care that can deal with the action to be performed, by synchronizing input data received from more than one smart device used, in which this experiment attempts to propose a decision support model that receives input queue model of the data obtained from the patient or from the device used by the patient, so it can be given the decision what action will be done by the patient (in this case can be said that is in the patient's location or patient's family) and what action will be the servant (in this case is the hospital management section).

\section{Smart City and Smart Health Care}

A lot of questions about smart city, what is a smart city and why do many people discuss it? In recent years there has been an explosive growth in ICT information and communications technology due to technological advances and hardware and software design. The use of ICTs in cities in various forms for various urban activities has led to increased effectiveness of city operations and these cities have been named using many different terms such as "cyberville", "digital city", "electronic city" "Flexicity", "information city", "telicity", "wired city",,"intelligent city", and "smart city". Smart City is the biggest abstraction among the names used, although some parts of the city only use the city state monitoring system. Smart City is a concept and there is still no clear and consistent definition of concepts among academics and practitioners. In a simple explanation, a smart city is a place where traditional networks and services are made more flexible, efficient, smart and sustainable with the use of information technology, digital and telecommunications, to improve operations for the benefit of the population. In other 
words, in a smart city, digital technology translates into better public services for the population, and for better use of resources while impacting less favorable environments [4].

The components of the smart city are: smart infrastructure, smar home, smart building, smart transportation, smart energy, smart health care, smart technology, smart governance, smart education, and smart citizens. Different smart cities have different levels of intelligent components, depending on their smart city focus. The various attributes of smart cities include sustainability, quality of life (Quality of Life/QoL), urbanization, and intelligence. The sustainability of an intelligent city is linked with municipal infrastructure and governance, energy and climate change, pollution and waste, and social, economic and health issues. Quality of Life (QoL) can be measured in terms of the emotional and financial well-being of citizens. The urbanization aspect of smart cities includes many aspects and indicators, such as technology, municipal infrastructure, government, and economics. The uniqueness of a smart city is conceptualized as an ambition to improve the economic, social and environmental standards of the city and its inhabitants. The most frequently cited aspects of city smartness include smart economy, smart people, smart governance, smart mobility, and smart living [4]. Development opportunities in smart health care include:

a) Data collection, so get the data presentation and then can be done data analysis

b) Prevention and management of critical events

c) Environmental Evaluation and Evaluation

d) Involve patient and patient families in managing their own health

e) Improve policy in decision making

f) Epidemic Control, and

g) Cost savings

Smart HealthCare applications as Smart e-Health solutions include:

a) Management records patient data electronicall

b) Management of hospital assets

c) Help for the elderly and disablepeople

d) Control the condition of medical equipment in the freezer

e) Monitoring the health of sports center users

f) Supervision of patient condition in hospital and outpatient

g) Control UV radiation for treatment

\section{Decision Support System on Smart Health Care}

High quality data and data security and information exchange are essential in health care. Smart organizations health services face critical impediments to data-based or analytical treatment decisions (such barriers include incomplete personal health data, siloed data / silage data / separate databases or collection of data files that are not part of the overall enterprise data administration, structured and unstructured data, and paper-based notes). In addition, organizations prioritize using data for business reporting in the hope of gaining greater benefits than medical decisions (evidence-based medicine). Efficient and effective operational support and decision-making systems are needed for all related partners [12].

Smart City is the result of a long chain of Decision and Decision Support Systems (DSS) used in large-scale project plans that develop traditional cities into smart cities. The Evaluation and Review Techniques Program is a widely used method for planning and coordinating large-scale projects. It is generally accepted that time, money, people, equipment and other equipment are needed to plan and execute a project. During a particular project research and design period, it is important to understand and follow a set of specific guidelines for the project, such as [13] :

a. All processes must have different starting and ending points

b. All estimates must be realistis c. The process should be arranged in the order specified that produces predefined results (critical path must be recognizable)

d. Resources can be diverted to meet the needs, and

e. Direct link in sharing cost and time (ie the cost of each activity is spread evenly over time).

Operational Smart City involves many decisions at the strategic, tactical and operational levels. Strategic decisions and tactics are often planned together in several projects, and useful decisions are the main objectives of the city government. Managers use DSS and CS (Collaborative Software) facilities for complex decision making. Usually this technical support is integrated in the dynamic development process from the perspective of urban planning and management, which requires DSS developers to continue to improve and provide new capabilities for a particular time or project perspective [13].

\section{Research Purposes}

The purpose of this research is to get Smart HealthCare model with Decision Support System model approach in public health service. Produce Decision Support System model for Smart Heatlh Care that can solve health service problem in order to produce maximum service to patient.

\section{Benefits of Research}

With the new model of Smart HealthCare based on the Decision Support System model approach it is expected to:

a. Optimize services for patients who experience sudden health problems

b. Optimizing the limited human resources for the better

c. Optimizing limited health facilities for the better

d. Empower patients to be more responsible for their health.

e. Optimizing cooperation among health service resources.

\section{Research Framework}

To obtain the result of the model used for smarthealth in accordance with the problems and objectives to be achieved, the following describes the research framework as a stage in the implementation of research from the beginning to the achievement of the final result. The research was divided into 3 stages :

a. Create a queuing model in public health services.

b. Create a Decision Support System model in public health service.

c. Combine the two models to get the Smart HealthCare model.

\section{M / G / S Queue with Non-Preemptive Pri- ority}

In Figure 2 Queue Model described priority in disease management is closely related to death and disability (eg heart attacks, strokes and accidents), mass casualties (eg fire, sinking vessels). The incidence experienced in the patients mentioned above was the handling that must be handled quickly, so called the patient's priority.

In health care is a queuing model with different patient types, in which one or more types of patients have priority over other types. It is more appropriate to consider the model M / G / 1 queue with $r$ type of patient. The priority type 1 patient is the highest priority handler, the priority type 2 customer is the second highest priority customer and so on [14]. 


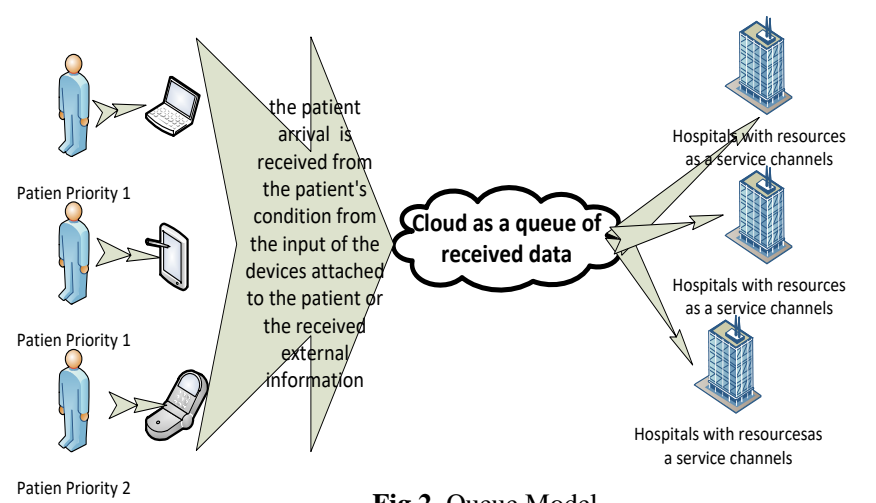

Fig 2. Queue Model

\section{The Design of a Decision Support System Model for Smart Health Care}

In Figure 3 The design of a decision support system model for smart health care described the model of the decision support system for smart healthcare begins with the patient's data state input or data received from the patient-installed devices or socalled smart devices attached to the patient. the data will be received by the server handling the distribution of patient services, if the patient is a priority $1 /$ main which in this case has been cleared in the previous section then the patient must be immediately served and in priority at the nearest hospital connected to the server system, and on the condition is also proposed to promptly pick up the patient, and it is possible that the patient may be escorted by the patient's family or the nearest person is also encouraged, because in this case the first priority is to take first aid to the patient. Next, the distribution of patient care which is a priority 2 will be provided by the hospital services depending on the decision to be given by the system, where the consideration in the assessment is the availability of resources in the hospital, the availability of specialist doctors who handle the disease or the availability of polyclinics, the availability of equipment the required support and the availability of in-patient rooms that provide information on the type / class of the room. The following is presented framework of The design of a decision support system model for smart health care.
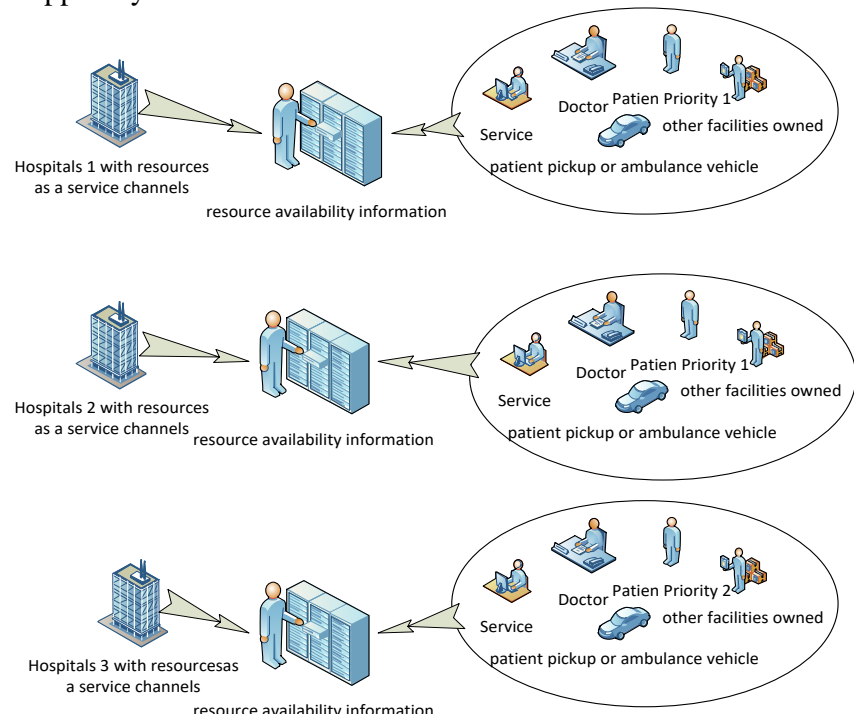

Fig 3. The design of a decision support system model for smart health Care

\section{Future Research Plan}

As for future research plan are:

a. Combine the proposed queuing model with the proposal model as decision support on smart health care.

b. Implementing the implementation with actual input data.

c. Refining the model

\section{Conclusion}

After describing the model results and simulating the model, can be obtained some conclusions as follows :

a. The handling of an emergency patient or the so-called priority patient 1 , prioritizes prompt action, as it relates to the safety of the patient's life.

b. While for the next patient condition categorized as patient priority 2 , will prioritize completeness of supporting facilities and infrastructure at hospital that will handle disease patient.

For the perfection of this research, there are several suggestions ie An in-depth study of the proposed model needs to be done.

a. Testing of input data needs to be done in order to maximize the results of the correct model.

b. The framework of this model will be further examined as a refinement of decision support models that benefit intelligent healthcare.

\section{References}

[1] X. Chen, L. Wang, J. Ding, and N. Thomas, "Patient Flow Scheduling and Capacity Planning in a Smart Hospital Environment," IEEE Access, vol. 4, pp. 135-148, 2016.

[2] C. Tekin, O. Atan, and M. Van Der Schaar, "Discover the Expert: Context-Adaptive Expert Selection for Medical Diagnosis," IEEE Trans. Emerg. Top. Comput., vol. 3, no. 2, pp. 220-234, 2015.

[3] F.-Z. Younsi, A. Bounnekar, D. Hamdadou, and O. Boussaid, "SEIR-SW, Simulation Model of Influenza Spread Based on the Small World Network," Tsinghua Sci. Technol., vol. 20, no. 5, pp. 460-473, 2015

[4] S. P. Mohanty, U. Choppali, and E. Kougianos, "Everything you wanted to know about smart cities," IEEE Consum. Electron. Mag., vol. 5, no. 3, pp. 60-70, 2016.

[5] A. Alaiad and L. Zhou, "Patients' adoption of WSN-Based smart home healthcare systems: An integrated model of facilitators and barriers," IEEE Trans. Prof. Commun., vol. 60, no. 1, pp. 4-23, 2017.

[6] L. Lapointe, J. Ramaprasad, and I. Vedel, "Collaborating through social media to create health awareness," in Proceedings of the Annual Hawaii International Conference on System Sciences, 2013, pp. 792-801.

[7] A. Solanas et al., "Smart health: A context-aware health paradigm within smart cities," IEEE Commun. Mag., vol. 52, no. 8, pp. 74-81, 2014.

[8] T. J. Kakiay, Dasar Teori Antrian Untuk Kehidupan Nyata. Yogyakarta: Andi, 2004

[9] A. M. H. Pardede, H. Mawengkang, and Z. Situmorang, "SIMULASI ANTRIAN KEDATANGAN BERKELOMPOK DENGAN PELAYANAN WEIBULL OLEH BANYAK SERVER," J. Teknol. Inf. dan Komun., vol. 3, no. 1, pp. 1-10, 2014.

[10] A. M. H. Pardede, Novriyenni, and R. Hartono, "SIMULASI ANTRIAN PELAYANAN NASABAH BANK MENGGUNAKAN METODE HYPEREXPONENTIAL," J. Inf. Syst. Dev., vol. 3, no. 1, pp. 33-43, 2018

[11] P. G. W. Keen, "Decision support systems: a research perspective," Decis. Support Syst. Issues Challenges Proc. an Int. Task Force Meet., pp. 23-44, 1980.

[12] H. Demirkan, "A smart healthcare systems framework," IT Prof., vol. 15 , no. 5 , pp. $38-45,2013$

[13] V. Chichernea, "THE USE OF DECISION SUPPORT SYSTEMS (DSS) IN SMART CITY PLANNING AND MANAGEMENT," $J$ Inf. Syst. Oper. Manag., pp. 1-14, 2014.

[14] I. Adan and J. Resing, "Queueing Theory," Technology, vol. 15, no. X, p. 180, 2002. 